\title{
STRATEGI PEMENANGAN CALEG PARTAI GERINDRA DALAM PEMILU LEGISLATIF 2019: STUDI KASUS BAMBANG PUJIANTO DAPIL 2 SIDOARJO
}

\author{
Bintang Widiowati ${ }^{1}$, Wisnu Pramutanto ${ }^{2}$ \\ ${ }^{1}$ Departemen Politik, Fakultas Ilmu Sosial dan Ilmu Politik, Universitas Airlangga \\ bintang.widiowati-2015@fisip.unair.ac.id \\ ${ }^{2}$ Departemen Politik, Fakultas Ilmu Sosial dan Ilmu Politik, Universitas Airlangga \\ wisnu.pramutanto@fisip.unair.ac.id
}

\begin{abstract}
The present study discusses the strategy of winning the Gerindra party candidates in Sidoarjo. In this case the problem that occurs is the struggle for the seat of Si-doarjo regency DPRD. In this thesis the researcher will explain the winning strat- egies, challenges and obstacles during the campaign process of the Gerindra party candidates. Seeing within the framework of the theory of Firmanzah which states that political marketing is divided into 4 programs (4P) namely: Product, Promo- tion, Price, Place. In this research, it will be seen how the winning strategy carried out by the Gerindra party candidates (Bambang Pudjianto) in electoral districts 2 of Sidoarjo regency, where he is an incumbent candidate who has advanced as a people's representative. His strategy is to rely on 3 products of political jargon; \# win us, the medical check-up program and aspiration stalls that reap the enthusias- tic response of citizens. With the strategy carried out by Bambang Pudjianto, he succeeded in attracting the sympathy of the people so that he was re-elected as the sidoarjo district parliament.
\end{abstract}

Keywordsi: Success team, General, Political strategy, Program.

\section{PENDAHULUAN}

Pemilu merupakan instrumen penting untuk menentukan rakyat memilih pemimpinnya. Undang-undang telah menjelaskan tentang fungsi Pemilu, yakni pemilihan anggota DPR, DPRD Provinsi dan DPRD Kabuputen/Kota. Pemilihan Umum 2019 dengan sistem proporsional terbuka menyebabkan persaingan ketat diantara caleg dalam satu dapil mereka. Persaingan ini mengakibatkan para caleg saling beradu strategi, taktik, dan metode pemenangan. Strategi politik adalah strategi yang digunakan untuk mewujudkan cita-cita politik. Tanpa strategi, kekuasan yang merupakan tujuan utama berpolitik tidak akan pernah terwujud. Konsolidasi partai politik menjadi modal utama caleg dalam meraup suara di dapil masing-masing pemenangan. Konsolidasi yang erat dan solid dari para parpol pendukung ini merupakan kunci kemenangan paslon. Kedua, strategi menjadi kunci utama kemenangan calon dalam mendulang suara dalam Pemilu. Strategi ialah pokok utama kemenangan dari caleg selain biaya politik. Strategi politik harus dapat terukur dengan perencanaan, monitoring, pelaksanaan, dan evaluasi.

Keberadaan kepemimpinan tokoh sebagai tonggak dan magnet pemilih menjadi kunci terpenting yang harus benar-benar disuguhkan di arena Pemilu. Seperti halnya caleg muda sekaligus petahana dari Partai Gerindra Kabupaten Sidoarjo. Bambang Pujianto merupakan caleg dan tokoh muda Kabupaten Sidoarjo yang mampu duduk sebagai wakil rakyat di DPRD Kabupaten Sidoarjo periode 2014-2019. Berangkat dari Partai Gerindra, beliau maju dari Dapil 2 Kabupaten Sidoarjo (Candi, Tanggulangin, Porong, dan Jabon). Ketokohan dan strategi beliau merupakan kunci kemenangan kedua 
merebut kursi DPRD Kabupaten Sidoarjo. Hal ini terbukti pada pemilu 2019, H. Bambang Pujianto, terpilih kembali meski hanya meraup 12.614 suara, kalah jauh dengan pendatang baru sesama caleg Partai Gerindra, H. Mimik Idayana, yakni 20.746 suara.

Terpilihnya kembali Bambang Pujianto sebagai anggota DPRD Kabupaten Sidoarjo tidak lepas dari modal citra tokoh muda, petahana, dan pimpinan DPD Partai Gerindra Kabupaten Sidoarjo yang mampu menaklukan dapil sengit wilayah 2 Kabupaten Sidoarjo. Dapil 2 Sidoarjo merupakan dapil baru bagi Bambang Pujianto. Dapil 2 merupakan dapil panas pada Pemilu 2014 dan 2019, terbukti tingginya money politics dan 10 petahana bersaing di dapil ini. Calon-calon sengit Dapil 2 seperti H Mimik Indayani (Gerindra), H Ainun Djariyah (PKB), Robiatul Adawiyah (PDIP), serta M. Maksum (PKB).

Strategi dalam menaklukan dapil yang ketat kerap kali digunakan strategi pencitraan seperti blusukan, kegiatan sosial, dan door to door. Perumusan strategi yang tepat dan kesolidan tim sukses menjadi kunci bagi Bambang waktu itu. Berdasarkan fenomena uraian di atas, maka peneliti tertarik untuk meneliti strategi pemenangan calon legislatif Partai Gerindra Kabupaten Sidoarjo dalam Pemilu 2019. Sebagai fokus peneliti ialah strategi caleg muda, H. Bambang Pujianto, yang terpilih kembali dengan penurunan suara signifikan.

\section{KERANGKA TEORI}

\section{Political Marketing}

Political marketing terdiri atas dua kata yaitu "political" dan "marketing". Political Marketing menurut Lock dan Harris dalam Inco Hary Perdana, "political marketing is concerned with communicating with party members, media, and prospective sources of funding as well as the electorate." Sedangkan Wring dalam Inco Hary Perdana (2012) mendefinisikan political marketing sebagai "the party or candidate's use of opinion research and enviromental analysis to produce and promote a competitive offering which will help realise organisational aims and satisfy groups of electors in exchange for their votes."

Menurut Laswell, komunikasi politik dihubungkan dengan political marketing. Political marketing merupakan bagian dari komunikasi politik. Political marketing digunakan dalam konteks dan tujuan yang lebih sempit, sehingga dapat dikatakan bahwa semua kegiatan political marketing merupakan bagian dari kegiatan komunikasi politik, sedangkan ada bagian lain dari komunikasi politik yang bukan merupakan kegiatan political marketing (Perdana, 2012). Penggunaan pendekatan marketing dalam dunia politik dikenal dengan marketing politik (political marketing). Dalam marketing politik, yang ditekankan adalah penggunaan pendekatan marketing untuk membantu politikus (dalam hal ini kandidat Pilkada) dan partai politik agar lebih efisien dan efektif dalam membangun hubungan dua arah dengan konstituen dan masyarakat. Hubungan ini diartikan sangat luas, dari kontak fisik selama periode kampanye sampai dengan komunikasi tidak langsung melalui pemberitaan di media massa. Marketing yang diadaptasi ke dalam dunia politik, dapat memberikan inspirasi tentang cara seorang 
kandidat dalam membuat produk berupa isu dan program kerja berdasarkan permasalahan-permasalahan yang sedang dihadapi masyarakat.

Seorang kandidat harus mampu menangkap keresahan dan permasalahan yang ada dalam kehidupan masyarakat. Dengan demikian, program-program yang mereka tawarkan bisa menjawab akar permasalahan yang ada dan juga mampu menumbuhkan keyakinan pemilih untuk memberikan suaranya kepada kandidat tersebut.

\section{Proses Politik Marketing}

Proses penerapan marketing dalam dunia politik juga mengadopsi program 4P yang telah lama dikenal dalam dunia bisnis. Penerapan program 4P bertujuan untuk membantu kandidat, mulai dari menganalisis dinamika masyarakat, memformulasikan program kerja, hingga penerapan strategi pada kelompok-kelompok masyarakat. Menurut Firmanzah menyebutkan bahwa program 4P terdiri dari Produk, Promosi, Price (Harga), dan Place (Tempat). Pertama, produk. Niffenegger membagi produk politik dalam tiga kategori, yakni (1) party flatform (platform partai), (2) past record (catatan tentang hal-hal yang dilakukan di masa lampau), dan (3) personal characteristic (ciri pribadi). Produk utama sebuah institusi politik adalah platform partai yang berisikan konsep, identitas ideologi, dan program kerja. Sedangkan Butler dan Collins menyatakan bahwa ada tiga dimensi penting yang harus dipahami dari sebuah produk politik, yaitu (1) person/party/ideology (pribadi/partai/ideologi), (2) loyalty (kesetiaan), dan (3) mutability (bisa berubah-ubah). Seorang kandidat, partai politik, dan ideologi partai adalah identitas sebuah institusi politik yang ditawarkan ke pemilih. Para pemilih akan mempertimbangkan mana yang mewakili suara mereka. Loyalitas pemilih adalah sesuatu yang ingin dicapai oleh sebuah institusi politik. Kandidat perlu menjaga kepercayaan pemilih agar pemilih tetap memberikan suaranya. Mutability atau berubah-ubah, berkaitan dengan persepsi pemilih terhadap kandidat.

Kedua, promosi. Dalam melakukan promosi produk yang mereka punya, partai politik atau kandidat (calon kepala daerah atau calon presiden) biasanya menggunakan media massa. Media massa seperti televisi menjadi sarana yang paling tepat untuk mempromosikan produk politik karena hampir seluruh masyarakat Indonesia saat ini telah dapat mengakses segala program televisi yang ada. Ketiga, harga. Niffenegger menjelaskan harga dalam marketing politik mencakup harga ekonomi, psikologis, dan citra nasional. Harga ekonomi berkaitan dengan biaya yang dikeluarkan dalam serangkaian proses marketing politik. Harga psikologis mengacu pada harga persepi psikologis, misalnya apakah pemilih merasa nyaman dengan latar belakang dari kandidat (etnis, agama, pendidikan, dan lain-lain) dari seorang kandidat. Harga citra nasional yang dimaksudkan adalah mengarah pada apakah pemilih merasa kandidat tersebut bisa memberikan citra positif suatu wilayah dan bisa menjadi kebanggaan bagi mereka. Keempat, tempat (place). Tempat berkaitan erat dengan cara hadir dan distribusi pesan dari kandidat ke masyarakat sebagai pemilih. Partai politik dan kandidat (presiden dan kepala daerah) 
mendistribusikan pesan dengan cara kunjungan ke daerah-daerah tertentu dan juga tempat-tempat seperti pasar tradisional.

\section{Kampanye Politik}

Kampanye merupakan suatu ajang manuver politik untuk menarik sebanyak mungkin pemilih dalam pemilu sehingga bisa meraih kekuasaan. Kampanye politik secara kasat mata digambarkan sebagai suatu proses interaksi intensif dari partai politik atau elite kepada masyarakat dalam kurun tertentu menjelang pemilihan umum (Firmanzah, 2012). Menurut Lilieker, kampanye politik adalah periode yang diberikan oleh panitia pemilu kepada semua konstestan, baik partai atau perorangan untuk memaparkan program-program kerja dan mempengaruhi opini publik sekaligus memobilisasi masyarakat agar memberikan suara kepada mereka sewaktu pencoblosan. Kampanye dalam pengartian ini sebagai pengumpulan massa parade dan orasi politik pengiklanan politik. Pengartian kampanye politik sebatas periode tertentu menjelang pemilihan umum mengandung beberapa kelemahan. Pertama, interaksi politik antara partai politik dan publik seolah-olah hanya terjadi pada periode tertentu. Padahal interaksi politik harus dilakukan konsisten. Kedua, kampanye politik adalah proses komunikasi politik dialogis antara partai politik dengan masyarakat. Apabila kampanye politik hanya sebatas kampanye pemilu, dikhawatirkan tidak terjadi kesamaan pemahaman dan persepsi di masyarakat. Pesan dan image politik yang terbangun ialah image lama (Firmanzah, 2012). Maka itu perlu pendefinisian dan pemahaman serta tindakan nyata dalam melakukan kampanye politik. Pertama, kampanye menjelang pemilu. Kampanye short-term ini digunakan sebagai ajang kompetisi jangka pendek menjelang pemilu untuk menggiring opini masyarakat. Kedua adalah kampanye yang bersifat permanen dan berlaku untuk jangka panjang. Dengan proses komunikasi politik terus menerus yang komprehensif dengan masyarakat maka akan melahirkan citra positif. Sebab, setiap tindakan dan kinerja output partai atau elite selalu dinilai dan disimpulakn oleh masyarakat baik melalui media sosial atau saluran aspirasi lainnya.

Menurut Lock, kampanye politik erat hubungannya dengan pembentukan image politik karena image politik perlu didukung oleh konsistensi aktivitas politik jangka panjang, kampanye politik pun harus dilakukan secara permanen dan tidak terbatas waktu menjelang Pemilu saja. Image politik yang akan dibangun harus memiliki karateristik sendiri dibanding pesaingnya. Perhatian kampanye politik tidak hanya terbatas pada periode tertentu tetapi harus sebelum dan sesudah pemilu untuk membangun image politik yang fungsinya dalam pencapaian suara konstituen pada pemilihan umum (Firmanzzah, 2012). 


\section{HASIL DAN PEMBAHASAN}

\section{Strategi Pemenangan Caleg Partai Gerindra (Bambang Pudjianto) dalam Pemilu Legislatif 2019 Tingkat II di Dapil 2 Kabupaten Sidoarjo}

Pemilihan umum calon legislatif di Kabupaten Sidoarjo berlangsung bersamaan dengan pemilihan DPR RI, DPD, DPRD Provinsi dan pemilihan presiden seperti di kota-kota lainnya secara serentak. Pesta demokrasi tahun 2019 yang lalu berlangsung secara serentak dan sukses di seluruh kota di Indonesia. Di Kabupaten Sidoarjo sendiri terbagi menjadi 6 dapil wilayah yang terdiri dari Dapil 1 (Sidoarjo, Buduran, dan Sedati), Dapil 2 (Candi, Jabon, Porong, dan Tanggulangin), Dapil 3 (Krembung, Prambon, Tulangan, dan Wonoayu), Dapil 4 (Tarik, Krian, dan Balong Bendo), Dapil 5 (Sukodono dan Taman), Dapil 6 (Waru dan Gedangan). Pesta demokrasi April 2019 lalu di Kabupaten Sidoarjo telah dipastikan berlangsung aman, tertib, dan lancar. Banyak peristiwa menarik dari proses pemilu di Kabupaten Sidoarjo. Hal-hal menarik dari proses pemilu tersebut banyak dijumpai dari tahapan kampanye sampai hari pencoblosan. Pada penelitian ini akan membahas proses kampanye calon legislatif DPRD Kabupaten Sidoarjo dari Dapil 2 meliputi Candi, Tanggulangin, Jabon, dan Porong. Tepatnya Bambang Pujianto, salah satu calon legislatif berasal dari Partai Gerindra yang maju dan mendapatkan kursi pada putaran Pemilu 2019 lalu. Bambang Pujianto merupakan kader dan sekretaris DPC Partai Gerindra Kabupaten Sidoarjo sekaligus merupakan calon petahana Dapil 2 Kabupaten Sidoarjo. Bambang Pujianto memiliki segala modal latar belakang yang kuat sebagai petahana dan mantan ketua Komisi B DPRD Kabupaten Sidoarjo tahun 2014-2019. Modal ini lantas tidak menjamin memuluskan langkah beliau kembali menduduki kursi wakil rakyat. Terbukti dengan perolehan suara Bambang Pujianto kalah dari pendatang baru yang juga berasal dari Gerindra, yakni H. Mimik Indayani yang berhasil mengantongi 20.746 suara.

Strategi dengar aspirasi dan menyerap isu dari akar rumput langsung dengan membentuk tim mahasiswa menjadi pilihan strategi Bambang Pujianto dalam merumuskan konsep strategi pemenangannya. Strategi yang tepat dan efisien menjadi taktik yang harus digunakan Bambang untuk pertarungan Dapil 2 Sidoarjo yang ketat. Pertarungan Dapil 2 dirasa Bambang cukup ketat dan panas, terbukti calon-calon yang maju Dapil 2 merupakan caleg-caleg yang berpotensi, seperti H. Mimik Indayani (Gerindra), H. Ainun Djariyah (PKB), Robiatul Adawiyah (PDIP), serta M. Maksum (PKB). Dapil 2 merupakan dapil baru bagi Bambang. Perumusan strategi yang tepat dan kesolidan tim sukses menjadi kunci bagi Bambang waktu itu.

Pertarungan Dapil 2 menjadi medan yang paling sulit bagi sebagian anggota dewan di Kabupaten Sidoarjo. Dengan berlatar belakang daerah industri dan masyarakat terdampak lumpur, menjadi tantangan bagi setiap dewan untuk merebut hati warga. Sikap apatis yang tidak partisipatif disebabkan kejadian lumpur lapindo menjadi medan terjal bagi dewan untuk meyakinkan warga Dapil 2. Pertarungan dengan 10 incumbent yang maju di dapil ini mengakibatkan gesekan serangan fajar atau money politic sangat besar. Kesolidan tim sukses dalam pemilu menjadi kunci utama dalam menghadapi 
persaingan sengit di Dapil 2. Berbekal ide kesolidan tim dari lawan internal partai, Bambang Pujianto mulai membentuk tim suksesnya dari kalangan mahasiswa dan karang taruna. Dari pembentukan tim mahasiswa itu, Bambang dapat merumuskan strategi yang tepat untuk menaklukan suara di Dapil 2 Sidoarjo. Bambang tidak terkesan dengan taktik-taktik konvensional seperti blusukan, sambang pasar, hadir di pengajian, serangan fajar, pemberian santunan anak yatim, dan sebagainya. Hal itu menurut Bambang sudah tidak laku di masyarakat.

Melalui tim suksesnya, Bambang lebih memilih menggunakan program kreatif dan kekinian, hal itu terbukti dengan bentuk program yang dihasilkan dari tim suksesnya. Menggunkan istilah tagar milenial "\#MenangkanKita" menjadi tagline grand design kampanye Bambang Pujianto. Tagline menangkan kita menjadi grand design utama promosi kampanye Bambang Pujianto untuk mengenalkan program kampanyenya. Konsep strategi menangkan kita menggunakan tiga pilar jargon kemenangan Bambang, yakni program medical check-up, Warung Aspirasi dan tagline \#MenangkanKita.

Seperti yang disampaikan Von Clausewitz menjelaskan bahwa tujuan strategi bukanlah merupakan kemenangan yang nampak di permukaan, melainkan kedamaian yang terletak di belakangnya. Perencanaan ini sangatlah penting bagi perencanaan strategi politik. Strategi itu sendiri selalu memiliki tujuan yaitu "kemenangan". Strategi terencana dan terstruktur dari Bambang dan tim suksesnya yang membalut program sosial dan membawa semangat sosial untuk pendukung dan non pendukungnya menggambarkan strategi politik yang digunakan untuk memengaruhi simpati dukungan kepada Bambang. Hal ini digambarkan dalam aktivitas kampanye yang dilakukan tidak terlalu membawa pesan politik yang banyak, bahkan Bambang sendiri tidak banyak berbicara atau pidato di depan warga pada saat baksos kesehatan berlangsung.

Pesan politik yang tidak disampaikan dalam bentuk pidato dan sambutan merupakan bentuk strategi sendiri bagi tim. Dalam pelaksanaan proses awal sampai akhir pencoblosan, tim dan Bambang Pujianto mengadopsi teori marketing politik. Proses marketing politik sebagai pesan politik yang disampaikan kepada masyarakat dengan berbagai cara yang terstruktur, sistematis, terencana, dan efisien dijalankan Bambang Pujianto beserta timnya dalam pertarungan Pileg 2019. Semua itu dapat kita lihat dari konsep dan produk marketing politiknya seperti tagar \#MenangkanKita, rogram kesehatan medical check-up, dan Warung Aspirasi. Proses penerapan marketing dalam dunia politik juga mengadopsi program 4P yang telah lama dikenal dalam dunia bisnis. Menurut Firmanzah menyebutkan bahwa program 4P terdiri dari Produk, Promosi, Price (Harga) dan Place (Tempat) yang dijelaskan pada uraian di bawah ini.

Pertaman, produk. Niffenegger membagi produk politik dalam tiga kategori, (1) party platform (platform partai), (2) past record (catatan tentang hal-hal yang dilakukan di masa lampau), dan (3) personal characteristic (ciri pribadi). Produk utama sebuah institusi politik adalah platform partai yang berisikan konsep, identitas ideologi, dan program kerja sebuah institusi. Produk politik yang ditampilkan oleh Bambang Pujianto ialah sosok figur yang mengedepankan program kepentingan sosial yang langsung ditujukan kepada kebutuhan dasar warga, yakni program medical check-up dan warung 
aspirasi. Strategi kampanye ini merupakan produk yag ditampilkan Bambang Pujianto dalam pagelaran Pemilu 2019. Strategi ini dilakukan dengan pembentukan tim sukses untuk mendukung produk program kampanye Bambang Pujianto. Bambang Pujianto lebih memilih kaum muda dari karang taruna dan mahasiswa untuk mempercayakan dan mendukung program kampanyenya.

Kedua, promosi. Dalam melakukan promosi produk yang mereka punya, partai politik atau kandidat (calon kepala daerah atau calon presiden) biasanya menggunakan media massa. Kegiatan kampanye Bambang Pujianto dilakukan dengan cara mengenalkan program sosial yang dengan tagline \#Menangkan Kita dengan tim sukses yang selalu memposting ke media sosial seperti Whattsapp, Instagram, dan Twitter. Ketiga, harga. Niffenegger telah menjelaskan bahwa harga dalam marketing politik mencakup harga ekonomi, psikologis dan citra nasional. Dalam upaya mendukung programnya, biaya politik yang digunakan Bambang lebih pada internal sendiri dan bantuan dari DPC. Biaya politik tersebut didapat selama program reses dan program Jasmas (Jaring Aspirasi Masyarakat) serta dana hibah yang dijalankan selama memerintah di Komisi B. Dana ini oleh Bambang digunakan untuk biaya kampanyenya dalam bentuk program medical check-up dan warung aspirasi serta biaya operasional tim sukses. Keemat, tempat (place) berkaitan erat dengan cara hadir dan distribusi pesan dari kandidat ke masyarakat sebagai pemilih. Partai politik dan kandidat (presiden dan kepala daerah) mendistribusikan pesan dengan cara kunjungan ke daerah-daerah tertentu dan juga tempat-tempat seperti pasar tradisional.

Kampanye Bambang Pujianto dilakukan di dua kecamatan, yakni Kecamatan Candi dan Tanggulangin. Pemilihan tempat prioitas menjadi kunci dalam mengamankan suara. Sehingga biaya politik dan tempat menjadi kendala utama Bambang dalam meraih hasil suara yang maksimal. Hal ini dilakukan karena dua kecamatan ini ialah basis prioritas Bambang Pujianto. Dari dua kecamatan ini Bambang Pujianto berhasil meraup 9.979 suara dari total 20.746 suara.

Kaitannya dengan skripsi ini, pertama, produk politik kampanye yang dihasilkan menjadikan citra Bambang Pujianto sangat dikenal warga melalui program Warung Aspirasi dan program kesehatan medical check-up. Kedua, harga yang dihasilkan dari proses kampanye politik tersebut sangat positif dan memberikan efek timbal balik dari perolehan suara Bambang Pujianto. Ketiga, tempat yang positioning warung aspirasi sebagai gerbang pembuka sosialisasi program kampanye Bambang Pujianto.

\section{Tantangan dan Hambatan yang Dihadapi Caleg Partai Gerindra (Bambang Pujianto) dalam Pemilu Legislatif Tingkat II di Dapil 2 Kabupaten Sidoarjo}

Pelaksanaan kampanye tidak berjalan mulus begitu saja, pasti ada kendala dan hambatan yang terjadi. Pertama, saat kampanye bersentuhan langsung dengan masyarakat adalah ketika tim dan Bambang Pujianto berbicara menyampaikan pesan politik sikap apolitis ditunjukkan oleh warga. Kedua, kesuksesan program medical check-up berimbas pada permintaan di luar kecamatan prioritas dalam realisasi program tersebut. Ketiga, hambatan persaingan sengit Dapil 2 dengan majunya 10 petahana serta sejarah Pemilu 2014 dimana Dapil 2 merupakan sarang money politic. Hambatan lain yang terjadi 
pada masa pelaksanaan kampanye adalah hambatan dalam tim kampanye khususnya pada dana kampanye. Tim sukses sering kali meminta dana tambahan untuk kegiatan kampanye, hal ini membuat Bapak Firman harus rela untuk memberikan dana tambahan.

Perjalanan proses kampanye secara garis besar tidak ada hambatan dan kendala yang serius yang dialami tim dan Bambang. Kendala-kendala yang dihadapi lebih pada kendala umum dan wajar dalam kontestasi Pemilu, seperti money politic dari pendukung, persaingan dapil yang ketat, dan budget uang tambahan dari tim sukses, serta sikap warga yang apatis dan tidak merespon adanya pidato dan sambutan politik.

\section{SIMPULAN}

Berdasarkan pembahasan mengenai strategi pemenangan caleg Partai Gerindra Kabupaten Sidoarjo (Bambang Pujianto), maka dapat disimpulkan beberapa pokok penting dari pembahasan tersebut, pertama, produk program politik kampanye yang dijalankan menjadikan citra Bambang Pujianto sangat dikenal warga melalui program Warung Aspirasi dan program kesehatan medical checkup. Produk program medical check-up dan Warung Aspirasi berhasil menghasilkan 20.746 suara. Kedua, promosi dalam proses kampanye politik menggunakan strategi media sosial dengan tagline \#MenangkanKita yang diterjemahkan dalam media sosial (Whattsapp, Instagram, Twitter, dan Facebook) dan banner, spanduk yang dipasang di berbagai desa di Kecamatan Candi dan Kecamatan Tanggulangin. Ketiga, dalam mendukung programnya, biaya politik yang digunakan Bambang lebih pada internal sendiri dan bantuan dari DPC. Biaya politik didapat dari Program Reses, Program Jasmas dan hibah dijalankan selama memerintah di Komisi B. Dana ini oleh Bambang digunakan untuk biaya kampanyenya serta biaya operasional tim sukses. Keempat, basis prioritas menjadi lokasi utama dalam menjalankan strategi program kampanye untuk mendulang suara yakni di Kecamatan Candi dan Kecamatan Tanggulangin. Dua kecamatan ini berhasil menyumbang separuh perolehan suara Bambang Pujianto sebesar 9.979 suara. Kedua, dalam perjalanan proses kampanye secara garis besar tidak ada hambatan dan kendala yang serius yang dialami tim dan Bambang. Kendala serius ditemui dalam persaingan ketat dengan lawan politik di Dapil 2 yang berasal dari internal partai maupun partai lain. Persaingan ketat Dapil 2 disebabkan majunya 10 incumbent pada Pemilu 2019 periode ini. Salah satu pesaing kuat pendatang baru bagi Bambang ialah H. Mikik Indayani. Persaingan ketat ini berujung pada money politic yang terjadi di Dapil 2, ditambah basis Dapil 2 pada Pemilu tahun 2014 memiliki angka money politic tertinggi di Sidoarjo. Persaingan ketat di Dapil 2 ini berdampak pada bengkaknya operasional dan biaya-biaya tambahan bagi tim sukses untuk memenangkan persaingan di Dapil 2. 


\section{DAFTAR PUSTAKA}

Ardial (2010) Komunikasi Politik. Jakarta: Indeks.

Arikunto \& Suharsimi (2006) Prosedur Penelitian Suatu Pendekatan Praktik Edisi Revisi. Jakarta: Rineka Cipta.

Cholisin \& Nsiwan (2012) Dasar-Dasar Ilmu Politik. Yogyakarta: Ombak.

Emzir (2010) Metodologi Penelitian Pendidikan: Kuantitatif dan Kualitatif. Jakarta: Rajawali Pers.

Firmanzah (2012) Marketing Politik antara Pemahaman dan Realitas. Jakarta: Yayasan Obor Indonesia.

KPU Daerah Kabupaten Sidoarjo (n.d.) Perolehan Hasil Suara: Hasil Pemilu. Diakses pada 2019, dari https://kpud-sidoarjokab.go.id/pages/perolehan-suara-hasil-pemilu-kpu-sidoarjo

Moleong LJ (2000) Metodologi Penelitian Kualitatif. Bandung: Remaja Rosdakarya.

Partai Gerindra (n.d.) Manifesto Perjuangan Partai Gerakan Indonesia Raya. Diakses pada 2018, dari http://partaigerindra.or.id/uploads/Manifesto-Perjuangan-Partai-Gerindra.pdf.

Perdana IH (2012) Political Marketing Partai Politik Baru Pemilu 2014. Jakarta: Universitas Indonesia (Skripsi).

Pito TA, Efriza, Fasyah K (2006) Mengenal Teori-Teori Politik. Bandung: Nuansa.

Prilleltensky I \& Dennis F (2005) Psikologi Kritis. Jakarta: Teraju.

Sastroatmodjo S (1995) Perilaku Politik. Semarang: IKIP Semarang Press.

Sugiyono (2013) Metode Penelitian Pendidikan Pendekatan Kuantitatif, Kualitatif, dan R\&D. Bandung: Alfabeta.

Suprayogo I \& Tobroni (2001) Metode Penelitian Kualitatif. Bandung: PT Remaja Rosdakarya.

Surbakti R (2010) Memahami Ilmu Politik. Jakarta: Grasindo. 